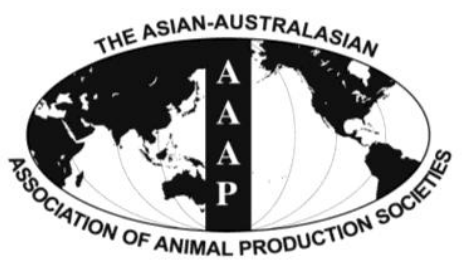

Open Access

Asian Australas. J. Anim. Sci.

Vol. 28, No. 8 : 1090-1094 August 2015

http://dx.doi.org/10.5713/ajas.14.0866

www.ajas.info

pISSN 1011-2367 elSSN 1976-5517

\title{
Genetic Variability of Show Jumping Attributes in Young Horses Commencing Competing
}

\author{
Tomasz Próchniak*, Iwona Rozempolska-Rucińska, Grzegorz Zięba, and Marek Lukaszewicz ${ }^{1}$ \\ Department of Biological Bases of Animal Production, University of Life Sciences in Lublin, 20-950 Lublin, Poland
}

\begin{abstract}
The aim of the study was to select traits that may constitute a prospective criterion for breeding value prediction of young horses. The results of 1,232 starts of 894 four-, five-, six-, and seven-year-old horses, obtained during jumping championships for young horses which had not been evaluated in, alternative to championships, training centres were analyed. Nine traits were chosen of those recorded: ranking in the championship, elimination $(\mathrm{y} / \mathrm{n})$, conformation, rating of style on day one, two, and three, and penalty points on day one, two, and three of a championship. (Co)variance components were estimated via the Gibbs sampling procedure and adequate (co)variance component ratios were calculated. Statistical classifications were trait dependent but all fitted random additive genetic and permanent environment effects. It was found that such characteristics as penalty points and jumping style are potential indicators of jumping ability, and the genetic variability of the traits was within the range of $14 \%$ to $27 \%$. Given the low genetic correlations between the conformation and other results achieved on the parkour, the relevance of assessment of conformation in fouryears-old horses has been questioned. (Key Words: Horse Breeding, Show Jumping, Variance Components)
\end{abstract}

\section{INTRODUCTION}

Due to the complexity of jumping performance, the issue of breeding value prediction has been addressed in many research papers (e.g. Koenen and Aldridge, 2002; Langlois and Blouin, 2004; Viklund et al., 2011). There are various approaches for assessment of the quality of show jumping horses. In Poland, the approaches comprise either performance test after 100-day training for stallions and 60day training for mares or the Polish Jumping Championships for Young Horses (PJCYH) or, rarely, both; breeding value is predicted only for horses that have attended training centres. The breeding value of an individual is predicted for general, jumping, and dressage indices comprising different sets of traits recorded at the final performance test. In the recent years, an alternative method for evaluation of sport ability has gained

\footnotetext{
* Corresponding Author: Tomasz Próchniak. Tel: +48-81-4456 753, Fax: +48-81-4456777, E-mail: tomasz-prochniak@wp.pl ${ }^{1}$ Institute of Genetics and Animal Breeding, Polish Academy of Sciences, Jastrzębiec, 05-552 Magdalenka, Poland.

Submitted Nov. 13, 2014; Revised Jan. 15, 2015; Accepted Feb. 27, 2015
}

importance - the PJCYH, where horses that have not attended training centres for various reasons are evaluated. Frequent amendments to the PJCYH rules referring to scoring of the individual traits and calculating the final score significantly impede the estimation of genetic parameters of traits evaluated during competitions.

Currently, given the growing interest among horse breeders and riders in PJCYH scores, it seems advisable that a model for prediction of the breeding value of horses starting in the PJCYH should be developed. The choice of traits included in the breeding programme requires knowledge of their genetic variability and information about correlations between the traits (e.g., Thorén Hellsten et al., 2006).

The aim of the study was to select traits out of those recorded during $\mathrm{PJCYH}$ that may constitute a prospective criterion for genetic evaluation of jumping ability of young horses.

\section{MATERIALS AND METHODS}

The investigation involved 1,232 starts of 894 four-, five-, six-, and seven-years-old horses taking part in the

Copyright @ 2015 by Asian-Australasian Journal of Animal Sciences This is an open-access article distributed under the terms of the Creative Commons Attribution Non-Commercial License (http://creativecommons.org/licenses/by-nc/3.0/), which permits unrestricted non-commercial use, distribution, and reproduction in any medium, provided the original work is properly cited. 
PJCYH in the years 2005 through 2013 (Table 1). "Start" means participation of the horse in three days of championships in the year.

Two general types of show jumping rounds were practised during any championship - style assessing and precision jumping. The latter type of a round could have two variants-no allotted time (just penalty points for jumping faults) or against the clock (penalty for faults and for exceeding time allowance).

In an one and only round on each day of competition a horse could be evaluated for a set of traits out of nine traits evaluated in all age categories over three days of a championship (Table 2). The nine traits were: 1) overall ranking in the championship based on the scores obtained on each of the three competition days according to rules effective in given year; 2) elimination of a horse from the competition due to the second (or third - permissible only in competitions for younger horses with up to $125 \mathrm{~cm}$-high obstacles) refusal at an obstacle, or horse lameness; 3) to 5) rating of style on day one, two, and three comprising the sum of penalties (a half for pole knockdown, one for the first disobedience, two for the second disobedience, onetenth for each second of exceeded time) and bonus points granted by two judges of the jury for the jumping style; 6) to 8) penalty points on day one, two, and three scored either in regular precision jumping rounds or rounds against the clock (four for pole knockdown, four for the first disobedience, eight for the second disobedience permissible only in competitions with up to $125 \mathrm{~cm}$-high obstacles, one for each four started seconds of exceeded time), and 9) conformation (quality of walk and trot, and overall impression) of the four-year-old horses. Differences between the observation numbers for particular traits (Table 2) result primarily from switching between the two types of courses on consecutive days of a championship.

For the above traits we estimated the heritability $\left(h^{2}\right)$ and repeatability $\left(\mathrm{r}^{2}\right)$ coefficients, as well as the genetic correlations $\left(r_{g}\right)$ between them. Genetic correlations were estimated using a multi-trait model which takes into account nine analysed traits simultaneously.
Table 1. Number of horses and starts (in parentheses) across sex and age

\begin{tabular}{lccc}
\hline $\begin{array}{c}\text { Age category } \\
\text { (years) }\end{array}$ & $\hat{0}$ & $\uparrow$ & Total \\
\hline 4 & 264 & 166 & 430 \\
& $(265)$ & $(167)$ & $(432)$ \\
5 & 161 & 84 & 275 \\
& $(242)$ & $(164)$ & $(406)$ \\
6 & 89 & 56 & 145 \\
& $(155)$ & $(118)$ & $(273)$ \\
7 & 27 & 17 & 44 \\
& $(71)$ & $(50)$ & $(121)$ \\
Total & 541 & 353 & 894 \\
& $(733)$ & $(499)$ & $(1,232)$ \\
\hline
\end{tabular}

Statistical models for (co)variance component estimation were decided following introductory runs of analysis of variance testing the significance of identifiable effects (Table 3). The pedigree comprised 23,242 entries with a minimum depth of four generations for a single horse.

The variance components were estimated via Gibbs sampling with flat priors, employing the THRGIBBS1F90 software of Tsuruta and Misztal (2006). Three hundred thousand sampling rounds were run for all the models. Convergence was determined by visual inspection of trace plots, and 50,000 first iterations were discarded as burn-in.

\section{RESULTS AND DISCUSSION}

The overall ranking heritability coefficient of 0.14 (Table 4) can be considered moderate. A possibility, however, exists that its magnitude is in fact higher as the frequent changes to the PJCYH rules, e.g. introduction of assessment of the jump style, have introduced some noise to the consistency of the trait and horse ranking would be somewhat different in the consecutive years if the rules were stable. However, it was impossible to take these changes in the rules into account due to the insufficient number of observations within particular variants of a trait. Nevertheless, the trait is of limited use in an objective assessment of an individual. Low repeatability of the

Table 2. Simple statistics of the traits recorded during the Polish Jumping Championships for Young Horses

\begin{tabular}{|c|c|c|c|c|c|c|c|}
\hline Trait & & $\bar{x}$ & $\begin{array}{l}\text { Standard } \\
\text { deviation }\end{array}$ & Min & $\operatorname{Max}$ & Number of horses & Number of starts \\
\hline Overall ranking & (linear) & - & - & 1 & 49 & 894 & 1,232 \\
\hline Elimination & (threshold) & 0.18 & 0.39 & 0 & 1 & 894 & 1,232 \\
\hline Conformation & (linear) & 1.18 & 0.09 & 0.90 & 1.38 & 429 & 431 \\
\hline Day 1 style & (linear) & 7.09 & 1.08 & 1.10 & 8.80 & 203 & 388 \\
\hline Day 2 style & (linear) & 7.29 & 1.02 & -0.60 & 9.20 & 586 & 715 \\
\hline Day 3 style & (linear) & 7.18 & 1.35 & -1.90 & 9.20 & 527 & 623 \\
\hline Day 1 penalties & (linear) & 4.21 & 5.26 & 0 & 36.00 & 247 & 385 \\
\hline Day 2 penalties & (linear) & 4.52 & 5.29 & 0 & 27.00 & 252 & 401 \\
\hline Day 3 penalties & (linear) & 5.52 & 5.30 & 0 & 25.00 & 191 & 324 \\
\hline
\end{tabular}


Table 3. Effects ${ }^{1}$ fitted in the models for 3 groups of traits

\begin{tabular}{|c|c|c|c|c|c|}
\hline Traits & No. of classes & Type of effect ${ }^{2}$ & Ranking & $\begin{array}{c}\text { Elimination } \\
\text { Style score (day } 1,2,3) \\
\text { Penalties (day } 1,2,3)\end{array}$ & Conformation \\
\hline Additive genetic & 23,242 & A & $\mathrm{x}$ & $\mathrm{x}$ & $\mathrm{x}$ \\
\hline Permanent environment & $191-894$ & $\mathrm{R}$ & $\mathrm{x}$ & $\mathrm{x}$ & $\mathrm{x}$ \\
\hline Rider & 326 & $\mathrm{R}$ & $\mathrm{x}$ & $\mathrm{x}$ & \\
\hline Championship year & 9 & $\mathrm{~F}$ & $\mathrm{x}$ & $\mathrm{x}$ & $\mathrm{x}$ \\
\hline Site of the championships & 3 & $\mathrm{~F}$ & $\mathrm{x}$ & $\mathrm{x}$ & $\mathrm{x}$ \\
\hline Age category & 4 & $\mathrm{~F}$ & $\mathrm{x}$ & $\mathrm{x}$ & \\
\hline Sex & 3 & $\mathrm{~F}$ & $\mathrm{x}$ & $\mathrm{x}$ & $\mathrm{x}$ \\
\hline Number of competing horses & & $\mathrm{C}$ & $\mathrm{x}$ & & \\
\hline
\end{tabular}

${ }^{1} \mathrm{x}$ - presence of an effect in the model for particular trait.

${ }^{2}$ A, random, associated with relationship matrix; R, random, diagonal; F, fixed; C, fixed covariate.

ranking confirms that the rank depends on many environmental factors independent of an animal which the "background", i.e. the sport performance of competitors is probably of greatest importance. There are high beneficial genetic correlations between the ranking and penalty and style points (Table 5), but the overall ranking includes both of these traits.

The magnitudes of the estimated genetic correlations indicate that the rank in the group of competing horses is largely dependent on jumping precision and refusals at obstacles which, additionally, may be indicative of a horse's temperament. In that, our results confirm the findings reported by Górecka-Bruzda et al. (2011), Górecka-Bruzda and Jezierski (2010). Horse's overall ranking in a championship is greatly determined by penalty scores, i.e. precision and time as well as by the style of covering the course. It appears that these are traits largely determined by the additive genetic effect of an individual (Table 4), thus they can be used as selection criteria for genetic improvement of sport horses. The low genetic correlations within the penalty points on each day of the championships confirm the distinctiveness of these traits. The same holds for the style scoring. The highest heritability estimate of $h^{2}$ $=0.27$ was found for the "day three penalties" trait. Undoubtedly, on competition day three horses are expected to express their potential more fully having accustomed to

Table 4. Estimates of heritability $\left(h^{2}\right)$, repeatability $\left(r^{2}\right)$, and their standard errors (SE) for the analysed traits

\begin{tabular}{lcccc}
\hline Trait & $\mathrm{h}^{2}$ & $\mathrm{SE}$ & $\mathrm{r}^{2}$ & $\mathrm{SE}$ \\
\hline Overall ranking & 0.14 & 0.02 & 0.19 & 0.03 \\
Elimination & 0.00 & 0.00 & 0.26 & 0.05 \\
Conformation & 0.08 & 0.04 & 0.16 & 0.05 \\
Day 1 style & 0.26 & 0.06 & 0.44 & 0.07 \\
Day 2 style & 0.14 & 0.03 & 0.28 & 0.05 \\
Day 3 style & 0.16 & 0.03 & 0.40 & 0.05 \\
Day 1 penalties & 0.20 & 0.05 & 0.46 & 0.05 \\
Day 2 penalties & 0.19 & 0.04 & 0.40 & 0.05 \\
Day 3 penalties & 0.27 & 0.05 & 0.47 & 0.05 \\
\hline
\end{tabular}

the competition site environment. So, the third day results may provide even more objective information about the abilities of an individual. Simultaneously, high repeatability of these traits is indicative of the predisposition of a horse for show jumping as both additive genetic and permanent environment effects contribute to its value. Estimates of genetic parameters based on penalty points are comparable very much with the scores achieved in regular show jumping competitions. As such they may provide information on the jumping abilities of siblings and offspring of an evaluated horse (Wallin et al., 2003; Ducro et al., 2009).

A group of traits essential for horse overall ranking is also the style rating on consecutive days of championships (Table 5). According to the binding rules, four- and fiveyear-old horses are evaluated in the so-called "horse style assessment competitions". This comprises the sum of penalties for the faults committed on the parkour (pole knockdown, jump refusal, exceeding the time limit) and bonus points for style. The bonus points for style is a subjective measure and includes such elements as maintaining a steady pace of galloping, position of neck and back during the jump (bascule), horse's sensitivity to rider's assistance, and precision of overcoming obstacles, absence of which is manifested by e.g. touching the pole usually without a knockdown. The trait defined as the jump style (evaluated on day one) exhibits moderate heritability and repeatability (Table 4). However, fluctuation of the estimated heritability coefficient (from 0.14 to 0.26 ) was observed for this trait during the consecutive days of the championships. Simultaneously, a very low correlation was found between the jump style scores achieved on the consecutive days at decently high repeatabilities on each evaluation day; in particular on day one and three. It could be expected that style rating on each day of competition is a manifestation of the same trait at correlations close to unity. Apparently our results suggest that different components are in fact assessed on the consecutive days, and the style ratings on days one, two, and three are indeed determined 
Table 5. Genetic correlations (above) and their standard errors (below) between the traits

\begin{tabular}{|c|c|c|c|c|c|c|c|c|}
\hline & Ranking & Elimination & Conformation & Day 1 style & Day 2 style & Day 3 style & $\begin{array}{c}\text { Day } 1 \\
\text { penalties }\end{array}$ & $\begin{array}{c}\text { Day } 2 \\
\text { penalties }\end{array}$ \\
\hline Elimination & $\begin{array}{r}-0.01 \\
0.17\end{array}$ & & & & & & & \\
\hline Conformation & $\begin{array}{r}-0.17 \\
0.18\end{array}$ & $\begin{array}{r}-0.01 \\
0.17\end{array}$ & & & & & & \\
\hline Day 1 style & $\begin{array}{r}-0.66 \\
0.10\end{array}$ & $\begin{array}{l}0.01 \\
0.16\end{array}$ & $\begin{array}{l}0.03 \\
0.21\end{array}$ & & & & & \\
\hline Day 2 style & $\begin{array}{r}-0.56 \\
0.11\end{array}$ & $\begin{array}{l}0.01 \\
0.16\end{array}$ & $\begin{array}{l}0.16 \\
0.21\end{array}$ & $\begin{array}{l}0.31 \\
0.16\end{array}$ & & & & \\
\hline Day 3 style & $\begin{array}{r}-0.60 \\
0.09\end{array}$ & $\begin{array}{l}0.01 \\
0.18\end{array}$ & $\begin{array}{l}0.04 \\
0.21\end{array}$ & $\begin{array}{l}0.35 \\
0.16\end{array}$ & $\begin{array}{l}0.27 \\
0.15\end{array}$ & & & \\
\hline Day 1 penalties & $\begin{array}{l}0.46 \\
0.15\end{array}$ & $\begin{array}{r}-0.01 \\
0.16\end{array}$ & $\begin{array}{r}-0.07 \\
0.25\end{array}$ & $\begin{array}{r}-0.29 \\
0.18\end{array}$ & $\begin{array}{r}-0.21 \\
0.18\end{array}$ & $\begin{array}{r}-0.26 \\
0.17\end{array}$ & & \\
\hline Day 2 penalties & $\begin{array}{l}0.82 \\
0.05\end{array}$ & $\begin{array}{r}-0.01 \\
0.18\end{array}$ & $\begin{array}{r}-0.08 \\
0.22\end{array}$ & $\begin{array}{r}-0.25 \\
0.18\end{array}$ & $\begin{array}{r}-0.29 \\
0.15\end{array}$ & $\begin{array}{r}-0.39 \\
0.13\end{array}$ & $\begin{array}{l}0.23 \\
0.17\end{array}$ & \\
\hline Day 3 penalties & $\begin{array}{l}0.66 \\
0.10\end{array}$ & $\begin{array}{l}0.00 \\
0.19\end{array}$ & $\begin{array}{r}-0.16 \\
0.21\end{array}$ & $\begin{array}{r}-0.56 \\
0.15\end{array}$ & $\begin{array}{r}-0.37 \\
0.16\end{array}$ & $\begin{array}{r}-0.39 \\
0.14\end{array}$ & $\begin{array}{l}0.33 \\
0.17\end{array}$ & $\begin{array}{l}0.45 \\
0.14\end{array}$ \\
\hline
\end{tabular}

differently. A vague definition of the jump style can impede appropriate and unambiguous evaluation by a judge. On the other hand, the style rounds run by a horse on different days of championship are spread across horse's age (difficulty of a run) and championship sites. In practice, each day of the competition, horses are faced with obstacles giving a different optical impression, which are additionally arranged in different configurations. Therefore, faultless completion of a competition on each of the championship days requires slightly different predispositions. This can explain the low correlations between single trait scores on different days. An analogous situation was recognised in the trait of penalties scored during the consecutive days. Undoubtedly, in this case, the low correlations are caused by the competition type (against the clock/not against the clock). Although in both cases the score is based on penalties, the time is decisive in competitions against the clock. This can lead to a situation, in which horses scoring certain points in competitions not against the clock may commit more faults in competitions against the clock, where the rider shortens the route in order to achieve the best time. Consequently, on different days different traits can contribute to faults and determine the final score. In fact, penalty points inform about not only the jumping precision but also the ability to concentrate, physical and mental strength, and other biological predispositions that are difficult to identify unambiguously. Simultaneously, penalty points are closely related to the jump style (Table 5), which is obvious, as penalties are components of the jump style determining the value of the trait. Negative genetic correlations were observed between the style score and penalties scored by horses for faults committed on the course in competitions evaluated in accordance with the rules of the Polish Equestrian Federation. The highest correlation was obtained between the day one style score and day three penalties. This implies that horses with the best jump style are also characterised by sensitivity and precision in overcoming obstacles.

Another studied trait was elimination of a horse from the competition. The most common cause of elimination is the third refusal to jump and, less frequently, an animal injury or rider's withdrawal. The proportion of animals eliminated from the competition was $4.62 \%, 32.51 \%$, $20.15 \%$, and $19.83 \%$ in the group of four-, five-, six-, and seven-year-old horses, respectively. Since the heritability of elimination is practically non-existing (Table 4) elimination of a horse from competition may imply insufficient preparation of the animal for particular competition class. Moreover, it is vital for the organisers, horse owners, and competitors that all horses should finish championships. This undoubtedly increases their value, whereas elimination (in particular due to disobedience) is interpreted as lack of sport aptitude. These circumstances have an impact of the Course Designer's work, whose task is to match the difficulty of the parkour to the age group and number of horses in each age group. It should also be noted that elimination and the other traits are not genetically correlated ( $\mathrm{rg}=-0.01$ to 0.01 , Table 5). This proves that the trait mainly depends on environmental factors and is not a result of an additive effect on certain predispositions of the individual. Therefore, this trait is of little importance in assessment of the breeding value of sport horses.

In horse breeding, great importance is still attached to proper conformation. During the PJCYH, four-year-old horses undergo "arena assessment", at which a commission of three judges scores the horses for type and conformation, overall impression, and the quality of walk and trot. The heritability of conformation was estimated at $h^{2}=0.08$. The 
heritability values lower than those reported by Ducro et al. (2009) can be explained by the usage of only a part of the available scale by the judges while evaluating conformation during PJCYH. The subjectivity of the assessment prevents judges from differentiation of horses. On the other hand, the evaluation comprises also the so-called overall impression, where exclusively environmental traits are assessed, e.g. animal fitness and hoof grooming. An interesting phenomenon is the low correlation between the conformation score and sport performance (Table 5), also observed by other authors (Koenen et al., 1995; Ducro et al., 2009). The principles and relevance of the assessment of conformation in four-year-old horses at PJCYH is debatable, since horses are subjected to this type of evaluation at an earlier age.

Unfortunately, due to the very small number of horses that had competed repeatedly in PJCYH, it was impossible to estimate correlations between the assessments in the 4th, 5th, 6th, and 7th year of horse's life. Similar investigations conducted by Huizinga et al. (1989) on Dutch horses demonstrated repeatability of $r^{2}=0.75$.

\section{CONCLUSION}

The current results indicate that decisive effect upon horses' overall evaluation exert precision, speed, and environment factors. These elements primarily contribute to traits defined as "penalties" and "jump style". The $14 \%$ to $27 \%$ genetic variability of these traits is a good prognosis for their effective usage in breeding work aimed at improvement of jumping performance in horses so, analysis of the style and penalties regarded as separate traits that reveal horses' predispositions is indispensable during the consecutive days of the championship. Concurrently, evaluation based on penalties is easy to perform and provides information about the most important predispositions of sport horses.

Given the low genetic correlations between the conformation and results scored on the parkour, the validity of evaluation of conformation in four-year-old horses should be considered; low heritability of this trait additionally points to serious shortcomings in the rating scale used.

\section{REFERENCES}

Ducro, B. J., E. P. C. Koenen, J. M. F. M. Van Tartwijk, and H. Bovenhuis. 2007. Genetic relations of movement and freejumping traits with dressage and show-jumping performance in competition of Dutch Warmblood horses. Livest. Sci. 107:227-234

Ducro, B. J., H. Bovenhuis, and W. Back. 2009. Heritability of foot conformation and its relationship to sports performance in a Dutch Warmblood horse population. Equine Vet. J. 41:139143

Górecka-Bruzda, A. and T. Jezierski. 2010. Breed differences in behaviour-related characteristics of stallions evaluated in performance tests. Anim. Sci. Pap. Rep. 28:27-36.

Górecka-Bruzda, A., M. H. Chruszczewski, T. Jezierski, and J. Murphy. 2011. Behaviour-related traits of Polish sport horse stallions participating in 100-day performance tests. Livest. Sci. 136:207-215.

Huizinga, H. A. and G. J. W. Van der Meij. 1989. Estimated parameters of performance in jumping and dressage competition of the Dutch Warmblood horse. Livest. Prod. Sci. 21:333-345.

Koenen, E. P. C. and L. I. Aldridge. 2002. Testing and genetic evaluation of sport horses in an international perspective. In: 7th World Congress Applied to Livestock Production, Montpellier, France. p. 23.

Koenen, E. P. C., A. E. Van Veldhuizen, and E. W. Brascamp. 1995. Genetic parameters of linear scored conformation traits and their relation to dressage and show-jumping performance in the Dutch Warmblood Riding Horse population. Livest. Prod. Sci. 43:85-94.

Langlois, B. and C. Blouin. 2004. Practical efficiency of breeding value estimations based on annual earnings of horses for jumping, trotting, and galloping races in France. Livest. Prod. Sci. 87:99-107.

Thorén Hellsten, E., Å. Viklund, E. P. C. Koenen, A. Ricard, E. Bruns, and J. Philipsson. 2006. Review of genetic parameters estimated at stallion and young horse performance tests and their correlations with later results in dressage and showjumping competition. Livest. Sci. 103:1-12.

Tsuruta, S. and I. Misztal. 2006. THRGIBBS1F90 for estimation of variance components with threshold and linear models. In: Proceedings of the 8th World Congress on Genetics Applied to Livestock Production, Belo Horizonte, Minas Gerais, Brazil. pp. 27-31.

Viklund, Å., A. Näsholm, E. Strandberg, and J. Philipsson. 2011. Genetic trends for performance of Swedish Warmblood horses. Livest. Sci. 141:113-122.

Wallin, L., E. Strandberg, and J. Philipsson. 2003. Genetic correlations between field test results of Swedish Warmblood Riding Horses as 4-year-olds and lifetime performance results in dressage and show jumping. Livest. Prod. Sci. 82:61-71. 